\title{
PENGARUH TERAPI RELAKSASI BENSON TERHADAP SKALA NYERI DISMENORE PADA MAHASISWI KEPERAWATAN STIKES St. ELISABETH SEMARANG
}

\author{
Nur Malita Ulfa' ${ }^{1}$ Apolonia Antonilda Ina ${ }^{2}$, Andri Kenti Gayatina ${ }^{2}$ \\ ${ }^{1}$ Mahasiswa S1 ilmu Keperawatan STIKES St.Elisabeth Semarang \\ ${ }^{2}$ Dosen tetap STIKES St.Elisabeth Semarang
}

\section{Article Info}

Article History:
Accepted May 31th 2021

Keyword:

Dismenore, relaksasi Benson

\begin{abstract}
Background : Dysmenorrhea is pain in the abdomen its under parts are often experienced women at menstrual, obtained the average $50 \%$ of women luminance countries experienced dysmenorrhea and indonesia there are 55 $\%$.One way to reduce dysmenorrhea to conduct relaxation Benson. Therapy relaxation Benson proved to be sent down pain after surgical and had never been tested to overcome pain dysmenorrhea. The purpose of this research to know the influence of relaxation Benson to scale pain dysmenorrhea in a student of nursing STIKES St.Elisabeth Semarang.
\end{abstract}

Method :The methodology used in this research is quantitative by using quasy experiment design in which the reasearcher used pre and post test design involving one group of deciding sample by purposive sampling with 67 samples of Slovin calculation. Data normality testing is using Shapiro-Wilk. Bivariat analysis is using Wilcoxon testing alternative.

Result:Wilcoxon testing showed that $p<0,000$ meaning that there was difference in dismenore pain scale before and after Benson relaxation carried out by students with dismenore. The average of dismenore pain scale before the treatment was 5,51 dan that of after the treatment was 3,67

Conclusion: There is an influence of Benson relaxation effect on the dismenore pain scale at STIKES St.Elisabeth Semarang $(p<0,05)$.

Corresponding author:

Nur Malita Ulfa-

Jurnal Ilmu Keperawatan Maternitas, Vol 4 No 1, May 2021

DOI: http://dx.doi.org/10.26594/jikm.1.2.2018.278

e-ISSN 2621-2994 


\section{A. PENDAhuluan}

Masa remaja merupakan periode terjadinya pertumbuhan dan perkembangan baik secara fisik, psikologis maupun intelektual. ${ }^{1}$

Wanita secara normal pada usia subur akan mengalami menstruasi setiap bulan. Namun pengalaman menstruasi ini akan berbeda-beda antara satu dengan yang lainnya. Sebagian wanita mendapatkan menstruasi tanpa keluhan, sebagian besar yang lain mendapatkan menstruasi disertai dengan keluhan nyeri kram pada abdomen bagian bawah yang terjadi selama haid dan disebut dengan nyeri haid dismenore. ${ }^{2}$

Prevalensi dismenore di dunia sangat besar, yaitu rata-rata lebih dari 50\% perempuan di setiap dunia mengalami dismenore. Presentase dismenore di Amerika Serikat tahun 2011 diperkirakan hampir $90 \%$ wanita mengalami dismenore. ${ }^{3}$

Menurut WHO (World Health Organization) negara Inggris 45-97\% wanita muda dengan keluhan dismenore, dimana prevalensi hampir sama ditemui di negara-negara Eropa. Prevalensi di Swedia tahun 2013 menunjukan sebanyak $72 \%$ wanita mengalami dismenore. ${ }^{4}$

Prevalensi di Malaysia sebanyak $62,3 \%$ wanita mengalami dismenore. wanita mengalami dismenore. Prevalensi di Indonesia tahun 2013 sebanyak 55\% wanita mengalami dismenore, namun yang berobat ke pelayanan kesehatan sangatlah sedikit, yaitu hanya $1 \%-2 \% .^{5}$ Berdasarkan sensus Badan Pusat Statistik Jawa Tengah tahun 2010 menunjukkan Provinsi Jawa Tengah terdapat $54,9 \%$ remaja putri mengalami dismenore. ${ }^{6}$

Upaya penanganan untuk mengurangi dismenore ada 2 cara untuk mengurangi nyeri pada saat haid yaitu secara farmakologi dan non farmakologi. Penanganan non farmakologi juga dapat dilakukan untuk mengurangi dismenore, salah satu yang bisa dapat dilakukan adalah dengan menggunakan relaksasi Benson.

Relaksasi Benson ini merupakan pengobatan untuk menghilangkan nyeri dengan upaya memusatkan perhatian pada suatu fokus dengan menyebut berulang-ulang kalimat yang diyakini dan menghilangkan berbagai pikiran yang mengganggu. ${ }^{8}$

Hasil studi pendahuluan yang dilakukan pada 31 mahasiswi remaja putri D3 tingkat 2 Stikes St.Elisabeth Semarang, hasil ini menunjukan angka prevalensi untuk penelitian tersebut adalah sebesar $69 \%$.

Relaksasi Benson mudah dilakukan kapan saja, tidak banyak memerlukan alat untuk melakukan ini, banyak manfaat yang didapatkan dari relaksasi Benson. Dari hasil studi pendahuluan dan juga banyaknnya manfaat relaksasi Benson untuk kesehatan seperti yang telah diuraikan diatas maka peneliti tertarik untuk melakukan penelitian ini dengan judul "Pengaruh terapi relaksasi Benson terhadap skala nyeri dismenore pada mahasiswi Keperawatan Stikes St.Elisabeth Semarang".

Populasi di penelitian ini adalah mahasiswi STIKES St.Elisabeth Semarang yang mengalami dismenore saat menstruasi sebanyak 210 mahasiswi. Cara perhitungan sampel menggunakan rumus Slovin sehingga didapatkan jumlah sampel 67 responden. Uji statistik menggunakan uji Wilcoxon.

\section{B. METODE PENELITIAN}

1. Desain Penelitian

Penelitian ini merupakan penelitian kuantitatif dilakukan secara quasi eksperimental dan metode design one group pre and post test design yaitu dengan menggunakan satu kelompok responden di mana kelompok tersebut diberikan perlakuan. Kelompok yang diteliti sebelumnya 
diukur skala nyerinya lalu diberi perlakuan teknik relaksasi Benson. Setelah diberikan perlakuan, nyeri diukur kembali. ${ }^{31}$

\section{Populasi dan Sampel}

Populasi

keseluruhan sumber data yang diperlukan dalam suatu penelitian. Populasi pada penelitian ini adalah mahasiswi STIKES St. Elisabeth Semarang yang mengalami dismenore saat menstruasi sebanyak 67 orang.

\section{Waktu dan Tempat}

Pengambilan data untuk penelitian ini dilakukan di STIKES St. Elisabeth Semarang pada tanggal 9 Juli 2018 sampai 27 Juli 2018.

\section{HASIL PENELITIAN}

\section{Usia Responden}

Tabel 3 Karakteristik responden berdasarkan Usia Bulan Juni 2018

\begin{tabular}{ccc}
\hline Umur & Frekuensi & Presentasi \\
\hline 18 tahun & 6 & 9,0 \\
19 tahun & 13 & 19,4 \\
20 tahun & 10 & 14,9 \\
21 tahun & 16 & 23,9 \\
22 tahun & 20 & 29,9 \\
23 tahun & 2 & 3,0 \\
\hline Jumlah & 67 & 100 \\
\hline
\end{tabular}

Tabel 3 dapat diketahui bahwa sebagian besar presentasi diatas menunjukan usia responden terbanyak dalam penelitian ini adalah usia 22 tahun dengan presentasi sebanyak 20 orang (29,9\%), sedangkan jumlah responden yang paling sedikit yang ikut dalam penelitian ini adalah usia 23 tahun sebanyak 2 orang dengan presentasi (3,0\%).

2. Lama Menstruasi dan Siklus Menstruasi Responden

Tabel 4 Karakteristik Lama menstruasi dan Siklus menstruasi berdasarkan Bulan Juni 2018

\begin{tabular}{lccc}
\hline Karakteristik & $\begin{array}{c}\text { Nilai } \\
\text { Minimal }\end{array}$ & $\begin{array}{c}\text { Nilai } \\
\text { Maksimal }\end{array}$ & Rerata \pm s.b \\
\hline $\begin{array}{l}\text { Lama } \\
\text { menstruasi }\end{array}$ & 5 & 8 & $6,45 \pm 0,86$ \\
\hline $\begin{array}{l}\text { Siklus } \\
\text { menstruasi }\end{array}$ & 28 & 34 & $29,20 \pm 1,39$ \\
\hline
\end{tabular}

Berdasarkan Tabel 4 dapat diketahui bahwa pada mahasiswi Stikes St.Elisabeth Semarang lama menstruasi responden dengan ratarata 6,45 $\pm 0,86$ hari. Lama menstruasi minimal responden adalah 5 hari dan lama menstruasi maksimal responden adalah 8 hari, dan dapat diketahui juga bahwa siklus menstruasi responden dengan rata-rata $29,20 \pm 1,39$ hari. Siklus menstruasi minimal responden adalah 28 hari dan siklus menstruasi maksimal responden adalah 34 hari.

3. Skala Nyeri Dismenore Sebelum dan Sesudah Relaksasi Benson Responden

Tabel 5 KarakteristikSkala Nyeri

Dismenore Sebelum dan Sesudah

Relaksasi Benson responden berdasarkan Bulan Juni 2018

\begin{tabular}{lccc}
\hline \multicolumn{1}{c}{ Karakteristik } & $\begin{array}{c}\text { Nilai } \\
\text { Minimal }\end{array}$ & $\begin{array}{c}\text { Nilai } \\
\text { Maksimal }\end{array}$ & $\begin{array}{c}\text { Rerata } \\
\pm \text { s.b }\end{array}$ \\
\hline $\begin{array}{l}\text { skala nyeri } \\
\text { sebelum } \\
\text { relaksasi Benson }\end{array}$ & 2 & 7 & $5,51 \pm 1,28$ \\
\hline $\begin{array}{l}\text { skala nyeri } \\
\text { sesudah } \\
\text { relaksasi Benson }\end{array}$ & 1 & 6 & $3,67 \pm 1,43$ \\
\hline
\end{tabular}

Tabel 5 dapat diketahui bahwa pada mahasiswi yang mengalami dismenore di Stikes St.Elisabeth Semarang skala nyeri sebelum dilakukan relaksasi Benson dengan rata-rata $5,51 \pm 1,28$. Skala minimal responden sebelum dilakukan relaksasi Benson adalah 2 dan skala maksimal nyeri sebelum relaksasi Benson adalah 7, dan pada 
mahasiswi yang mengalami dismenore sesudah dilakukan relaksasi Benson dengan rata-rata $3,67 \pm 1,43$. Skala minimal responden sebelum dilakukan relaksasi Benson adalah 1 dan skala maksimal nyeri sebelum relaksasi Benson adalah 6.

4. Perbedaan Skala Nyeri Dismenore Sebelum dan Sesudah Dilakukan Relaksasi Benson

Tabel 6 KarakteristikPerbedaan skala nyeri dismenore sebelum dan sesudah dilakukan relaksasi Benson pada mahasiswi keperawatan STIKES St.Elisabeth Semarang berdasarkan Bulan Juni 2018

\begin{tabular}{|c|c|c|c|}
\hline $\begin{array}{c}\text { Karakteristik skala } \\
\text { nyeri dismenore }\end{array}$ & $\mathrm{N}$ & Rerata $\pm S b$ & $P$ \\
\hline $\begin{array}{lr}\text { Skala nyeri } & \text { Dismenore } \\
\text { Sebelum } & \text { relaksasi } \\
\text { Benson } & \\
\end{array}$ & 67 & $5,51 \pm 1,28$ & \multirow{2}{*}{0,000} \\
\hline $\begin{array}{lr}\text { Skala nyeri } & \text { Dismenore } \\
\text { Sesudah } & \text { relaksasi } \\
\text { Benson } & \\
\end{array}$ & 67 & $3,67 \pm 1,43$ & \\
\hline
\end{tabular}

Berdasarkan grafik dapat diperlihatkan sebagai berikut:

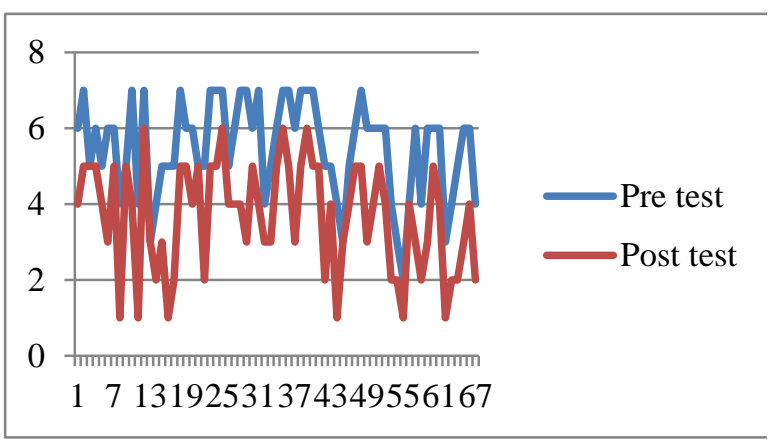

Gambar 4 Grafik perbedaan skala nyeri dismenore sebelum dan sesudah relaksasi Benson

Berdasarkan tabel 6 dan grafik 4 diatas dapat diketahui bahwa hasil uji alternatif Wilcoxon tersebut dapat diketahui perbedaan terhadap skala nyeri dismenore sebelum dan sesudah dilakukan relaksasi Benson pada mahasiswi Keperawatan
STIKES St.Elisabeth Semarang menunjukan $p$ value $0,000(p<0,05)$. Berdasarkan hasil uji Wilcoxon tersebut dapat ditarik kesimpulan bahwa $\mathrm{H}_{0}$ ditolak dan $\mathrm{H}_{1}$ diterima, yang menyatakan bahwa terdapat pengaruh skala nyeri dismenore sebelum dan sesudah dilakukan relaksasi Benson pada mahasiswi Keperawatan STIKES St. Elisabeth Semarang.

\section{PEMBAHASAN}

1. Karakteristik

Responden Berdasarkan Usia Responden

Dalam penelitian ini peneliti menetapkan usia responden 17-25 tahun. Gangguan ini akan mencapai puncaknya pada usia 17-25 tahun dan akan menghilang pada usia akhir 20-an atau 30-an tanpa ditemukan kelainan alat genital pada pemeriksaan ginekologi. 3,36

Dalam penelitian ini yang paling banyak mengalami dismenore usia 22 tahun dengan presentasi sebanyak 20 orang dimana dari 20 orang terdapat 7 orang responden yang mengalami penurunan skala nyeri yang paling banyak yaitu 3-4, sedangkan jumlah responden yang tidak banyak mengalami penurunan skala nyeri dismenore dalam penelitian ini berusia 23 tahun dengan presentasi sebanyak 2 orang dimana kedua orang responden mengalami penurunan yang tidak banyak yaitu 1 .

2. Karakteristik Responden Berdasarkan Siklus Menstruasi

Siklus menstruasi dipengaruhi oleh faktor psikis, pada remaja putri yang secara emosionalnya tidak stabil, apalagi jika mereka tidak mendapatkan penerangan yang baik tentang proses haid, mudah timbul dismenore. Ketidaksiapan remaja putri menghadapi perkembangan dan pertumbuhan pada dirinnya 
tersebut, mengakibatkan gangguan psikis yang akhirnnya menyebabkan gangguan fisiknya, misalnya gangguan haid seperti dismenore. ${ }^{38}$ Berdasarkan hasil penelitian didapatkan data siklus menstruasi responden terpanjang yang dialami oleh responden adalah 34 hari dan siklus menstruasi paling terpendek adalah 28 hari.

3. Karakteristik Berdasarkan Lama Menstruasi

Selain itu dismenore dapat dipengaruhi oleh lama menstruasi dapat disebabkan oleh faktor psikologis maupun fisiologis. Secara psikologis biasanya berkaitan dengan tingkat emosional remaja putri yang masih labil saat menstruasi. Secara fisiologis saat terjadi kontraksi otot uterus yang berlebihan atau dapat dikatakan sangat sensitif terhadap hormon ini akibat endometrium dalam fase sekresi memproduksi hormon prostaglandin. ${ }^{37}$

Semakin lama menstruasi terjadi, maka semakin sering uterus berkontraksi dan mengakibatkan keluarnya prostaglandin semakin banyak maka timbul rasa nyeri saat menstruasi. Hasil penelitian didapatkan data lama menstruasi responden terpanjang 8 hari dan lama menstruasi terpendek adalah 3 hari.

\section{Karakteristik Responden}

Berdasarkan Perbedaan Skala Nyeri Dismenore Sebelum dan Sesudah Dilakukan Relaksasi Benson

Berdasarkan hasil penelitian yang dilakukan pada 67 responden tentang pengaruh terapi relaksasi Benson terhadap skala nyeri dismenore. Perbedaan skala nyeri dismenore sebelum dan sesudah dilakukan relaksasi Benson pada mahasiswi keperawatan Stikes St.Elisabeth Semarang.

Perbedaan skala nyeri pre test dan post test menunjukan penurunan skala nyeri yang efektif, sehingga terapi relaksasi Benson dapat digunakan sebagai terapi non farmakologi bagi wanita yang mengalami dismenore primer. Selama penelitian peneliti mendapatkan 9 responden dilakukan penelitian dan observasi pada sore hari. Perbedaan waku penelitian ini menyebabkan penurunan skala nyeri masingmasing responden. Pada sore hari setelah selesai jam perkuliahan dan waktu beristirahat lebih banyak dan lebih lama. Istirahat dengan kondisi tubuh rileks akan mengeluarkan hormon endorphin yang memberikan efek nyaman sehingga dapat mengurangi nyeri. ${ }^{36}$

Dalam penelitian ini peneliti menjumpai 3 responden yang diobservasi pada siang hari saat responden sedang beristirahat selasela pergantian jam perkuliahan 3 responden tersebut tidak mengalami penurunan skala nyeri hal ini dapat disebabkan karena aktivitas yang berlebihan yang dilakukan responden dapat membuat kondisi tubuh kelelahan yang berakibat secara emosional tidak stabil sehingga saat merasakan nyeri akan sangat merasa kesakitan dan tidak ada perubahan skala nyeri yang dirasakan. Hal ini dapat disebabkan karena rasa lelah dan ketidak stabilan emosional sehingga sensasi nyeri tetap stabil dan intensif. Selain itu faktor endokrin dan faktor psikologis merupakan faktor perancu yang tidak dapat diukur oleh peneliti. Hormon endorphin dapat mengurangi sensasi nyeri dan kram perut akibat terjadi kontraksi 
uterus, kerja hormon endorphin dalam mengatasi nyeri adalah dengan menekan jumlah produksi prostaglandin sehingga melancarkan peredaran darah dalam uterus. Hormon endorphin juga memberikan energi positif menciptakan rasa senang dan membuat tubuh merasa nyaman, sirkulasi darah menjadi lebih lancar, tubuh akan menguraikan ketegangan otot, pikiran akan menjadi lebih tenang dan perasaan akan menjadi lebih tenang. ${ }^{19}$

Hasil dari penelitian yang sudah dilakukan tiap responden memiliki perubahan penurunan skala nyeri dismenore yang berbeda-beda, dimana pada responden 16 berusia 20 tahun dan responden 29 ini berusia 22 tahun mengalami penurunan skala nyeri yang paling besar dari responden lain sebesar 4 . Hasil wawancara kepada responden sebelum dilakukan intervensi relaksasi Benson responden 16 dan responden 29 ini 10 menit yang lalu selesai di lakukan observasi pengukuran nyeri dimana menunjukan hasil skala nyeri dismenore responden 16 yaitu skala 5 dan skala nyeri dismenore responden 29 yaitu skala 7 .

Penurunan skala nyeri dismenore pada responden 16 dan responden 29 ini terjadi selain karena kerja hormon endorphin yang dikeluarkan oleh tubuh juga dikarenakan sesuai teori intervensi relaksasi Benson ini menggunakan dua metode, yaitu dengan cara relaksasi yang dilakukan pada saat menarik nafas secara perlahan dan teratur secara bersamaan dengan menggabungkan cara distraksi untuk mengalihkan perhatian yang dapat menurunkan persepsi nyeri dengan mengulangi kata atau kalimat atau mungkin doa yang menjadi fokus. ${ }^{22}$ Responden 16 mengucapkan kata yang diyakini yaitu dengan bacaan "lailahaillallah" sedangkan responden 29 mengucapkan kata yang diyakini dengan bacaan "Puji Tuhan" dan dilakukan secara berulang sambil menghembuskan nafas dapat melancarkan peredaran darah keseluruh tubuh dan membuat rasa nyeri berkurang. ${ }^{19}$

\section{E. SIMPULAN}

Berdasarkan hasil penelitian dapat diambil simpulan bahwa:

1. Skala nyeri dismenore sebelum dilakukan intervensi relaksasi Benson rata-rata sebesar 5,51 nyeri sedang.

2. Skala nyeri dismenore setelah dilakukan intervensi relaksasi Benson rata-rata 3,67 nyeri ringan.

3. Ada perbedaan skala nyeri dismenore sebelum dan sesudah dilakukan relaksasi Benson pada mahasiswi Stikes St.Elisabeth Semarang.

\section{F. SARAN}

\section{Bagi Masyarakat}

Diharapkan

masyarakat khususnnya remaja putri dapat menggunakan relaksasi Benson sebagai suatu penanganan untuk menangani nyeri dismenore.

\section{Bagi Institusi Pendidikan}

Institusi pendidikan diharapkan dapat mengajarkan Relaksasi Benson untuk penanganan nyeri dismenore.

\section{Bagi Tenaga Kesehatan}

Dapat meningkatkan pelayanan kesehatan masyarakat khususnya pada wanita usia produktif tentang kesehatan reproduksi dengan memberikan informasi dalam mengatasi nyeri dismenore salah satunnya dengan menggunakan relaksasi Benson. 


\section{Penelitian selanjutnya}

Peneliti selanjutnnya dapat melakukan penelitian lebih lanjut mengenai relaksasi benson maka perlu dilakukan penelitian yang lebih lanjut dengan sampel yang lebih banyak dan populasi yang lebih luas dengan berbagai macam karakteristik responden yang jauh lebih bermacam juga tentang faktorfaktor (psikologis, konstitusi, keletihan, endokrin, pengetahuan) yang berhubungan dengan dismenore agar penelitian lebih baik dan lebih sempurna.

\section{G. REFERENSI}

1. Kementrian kesehatan RI. Situasi Kesehatan Reproduksi Remaja. Jakarta; 2016.

2. Schwartz MW. Pedoman Klinis Pediatri. Jakarta: Penerbit Buku Kedokteran EGC; 2009.

3. Kusmira E. Kesehatan Reproduksi Remaja dan Wanita. Jakarta Selatan: Salemba Medika; 2012.

4. Ningsih R. Efektifitas Paket Pereda Tahap Intensitas Nyeri Pada Remaja Dengan Disminorea di SMAN Kecamatan Curup. Jurnal Keperawatan Indonesia. 2013; 16 (2): 67-76.

5. Gui ZH. Prevalence of dysmenorrhea in female students in a Chinese university: Jurnal Health.2010; 4 (2): 311-314.

6. Badan Pusat Statistik Jawa Tengah. Demografi remaja putri. Jawa Tengah; 2010.

7. Prawirohardjo S. Ilmu kebidanan.Jakarta: Bina Pustaka; 2009.

8. Cahyono BS. Meraih Kekuatan Penyembuhan Diri Yang Tak
Terbatas. Jakarta: Pustaka Utama; 2011.

9. Potter PA \& Perry AG. Buku ajar fundamental keperawatan. Jakarta: Penerbit Buku Kedokteran EGC; 2010.

10. Yusliana A \& Safitri M. Efektivitas Relaksasi Benson Terhadap Penurunan Nyeri Pada Ibu Postpartum sectio Caesarea. Jurnal online Mahasiswa. 2015;3 (2): 1621.

11. Yanti. Buku Ajar Kesehatan Reproduksi. Yogyakarta: Pustaka Rihana; 2011.

12. Baziad A. Endokrinologi Ginekologi. Jakarta: Media Aesculapius; 2009.

13. Mitayani. Asuhan Keperawatan Maternitas. Jakarta: Salemba Medika; 2011.

14. Novia IP. Faktor Resiko Yang Mempengaruhi Kejadian Dismenorea. Journal of Public Health. 2008; 3 (4): 98.

15. Wiknjosastro. Ilmu Kebidanan. Jakarta: Yayasan Bina Pustaka; 2010

16. Mitayani. Asuhan Keperawatan Maternitas. Jakarta: Salemba Medika; 2011.

17. Wiknjosastro H. Ilmu Kandungan. Jakarta: Yayasan Bina Pustaka Sarwono Prawiroharjo; 2007

18. Erfina Y. Gambaran Tingkat Usia Terhadap Kejadian Disminore Pada Remaja Putri di Pondok Pesantren Darurrahman Sumatera. Jurnal Universitas Sumatera Utara.2011; 2 (4): 102-128.

19. Harry. Mekanisme Endrophin Dalam Tubuh. Jakarta: Bina Pustaka; 2008. 
20. Taufan N \& Utama BI. Masalah Kesehatan Reproduksi Wanita. Jogjakarta: Nuha Medika; 2014.

21. Sarwono. Gangguan Haid dan Siklusnya. Jakarta: Bina Pustaka; 2008.

22. Smeltzer \& Bare. Keperawatan Medikal Bedah. Jakarta: EGC; 2010.

23. Mander S. Nyeri Persalinan. Jakarta: Penerbit Buku Kedokteran EGC; 2009.

24. Hyman M. Ultra Metabolisme. Yogyakarta: B First; 2010.

25. Ernawati. Terapi Relaksasi Terhadap Nyeri Dismenore Pada Mahasiswi Universitas Muhammadiyah Semarang. Jurnal Prosiding Seminar Nasional Unimus. 2010; 2 (4): 85-96.

26. Sukmono RJ. Mendongkrak Kecerdasan Otak dengan Meditasi. Jakarta: Visimedia; 2011.

27. Mardini A. Buku Induk Doa Dzikir Amalan Para Nabi. Depok: Keira Publishing; 2017.

28. Paterson RM. Seri Tafsir Alkitab Kontekstual-Oikumenis. Jakarta: BPK Gunung Muria; 2017.

29. Pandita I. Doa Sehari-Hari Menurut Hindu. Denpasar: Redaksi Pustaka Geni; 2011.

30. Sugiyono. Metode Penelitian Kualitatif Kuantitatif dan R\&D. Bandung: Alfabeta; 2011.

31. Nursalam. Konsep dan Penerapan Metodologi Penelitian Ilmu Keperawatan. Jakarta: Salemba Medika; 2008.

32. Arikunto S. Prosedur Penelitian Suatu Pendekatan Praktek. Jakarta: PT. Rineka Cipta; 2010.
33. Notoadmojo S. Metodologi Penelitian Kesehatan. Jakarta: Rineka Cipta; 2010.

34. Hastono SP. Modul Analisis Data. Jakarta: FKM UI; 2010.

35. Ramod M \&Mohammadi PN. The effect of Benson's relaxation technique on the quality of sleep of Iranian hemodialysis patients. Journal Complementary Therapies in Medicine. 2013; 21 (6): 84-557.

36. Proverawati A \& Misaroh S. Menarche Menstruasi Pertama Penuh Makna. Jogjakarta: Nuhamed; 2009.

37. Gustina T. Hubungan antara Usia Menarche dan Lama Menstruasi dengan kejadian Dismenore Primer pada Remaja Putri di SMK. Journal Of Public Health. 2015; 3 (12): 87155.

38. Utami. Faktor-Faktor yang berhubungan dengan kejadian Dismenore pada Remaja Putri di SMAN 1 KAHU Kabupaten Bone. Jurnal Hasanuddin University. 2012; 4 (2): 98-167.

39. Rifki H. Faktor-Faktor yang mempengaruhi tingkat penurunan Nyeri Disminore. Jurnal Universitas Muhammadiyah Surakarta. 2014; 8 (2): 140.

40. Potter PA \& Perry AG. Fundamentals of Nursing: Concepts, Process, and Practice. USA: Mosby-Year BookInc; 2006.

41. Datak G. Penurunan Nyeri Pasca bedah TUR Prostat Melalui Relaksasi Benson. 2008. Jurnal Keperawatan Indonesia. 2008; 4 (2): 126-167. 